\title{
Research on Virtual Test of Automobile Automatic Emergency Braking System on Ice-Snow Road
}

\author{
Zhu Xianchao ${ }^{2}$, Chang Sheng ${ }^{1,2,}{ }^{*}$, Li Bingtao $^{2}$ and Lu Hualei ${ }^{3}$ \\ ${ }^{1}$ School of Automotive Engineering, Changshu Institute of Technology, Suzhou, Jiangsu, China \\ ${ }^{2}$ School of Mechanical Engineering, Jiamusi University, Jiamusi, Heilongjiang, China \\ ${ }^{3}$ School of Transportation and Automotive Engineering, Shandong University of Technology, Zibo, Shandong, China
}

\begin{abstract}
In view of the severe weather conditions in cold regions, the basic characteristics and braking distance of ice snow covered pavement are analyzed. This paper uses the PreScan/CarSim/Simulink software co-simulation method to test the automatic emergency braking (AEB) system on ice-snow roads. Through the appropriate adjustment of the time to collision (TTC) threshold, the car makes automatic emergency braking on the road with low friction coefficient system can achieve the effect of collision avoidance and injury reduction.
\end{abstract}

\section{Introduction}

Figure 1 is a map of the weather conditions in a certain area from 2011 to 2020 . The annual average temperature is $0^{\circ} \mathrm{C} \sim 11^{\circ} \mathrm{C}$, and the freezing and snowfall weather below $0^{\circ} \mathrm{C}$ accounts for $42.6 \%$ of the whole year ${ }^{[1]}$. At present, although the application of automatic emergency braking (AEB) system for automobiles is becoming more and more mature, there are relatively few test researches involving ice-snow road scenes. Therefore, this article mainly focuses on the road scenes under special severe weather conditions in cold areas to carry out test research.

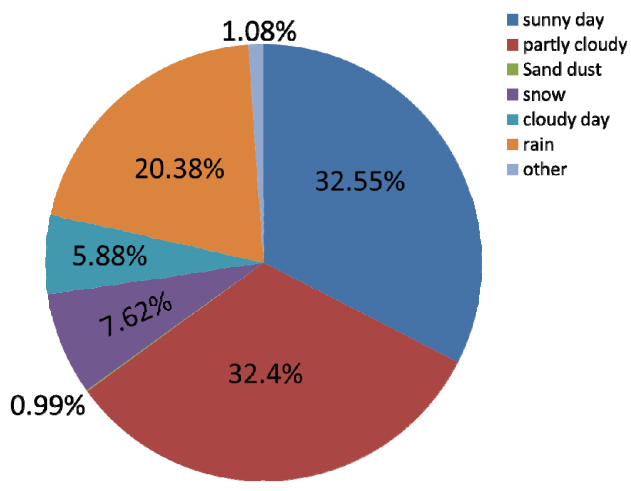

Figure 1 The distribution of weather conditions in a certain area from 2011 to 2020

\section{The influence of ice-snowy roads on braking distance}

\subsection{The characteristics of ice-snow roads}

When a car is driving on an ice-snow road, the ice and snow on the road reduces the friction coefficient between the tire and the road to a certain extent, which is particularly prone to cause traffic accidents. Table 1 is the friction coefficient table for the ice-snow road.

Table 1 Friction coefficient table of ice-snow road

\begin{tabular}{|c|c|}
\hline Road condition & $\begin{array}{c}\text { Friction } \\
\text { coefficient }\end{array}$ \\
\hline Ice road & $0.10 \sim 0.25$ \\
\hline Soft snow road & $0.20 \sim 0.40$ \\
\hline Compacted snow pavement & $0.15 \sim 0.25$ \\
\hline Wet pavement after melting snow & $0.40 \sim 0.50$ \\
\hline
\end{tabular}

\subsection{Analysis of vehicle braking distance on ice- snow road}

The formula for the total braking distance of the car is

$$
d=\frac{1}{3.6}\left(t_{21}+\frac{t_{22}}{2}\right) v_{0}+\frac{v_{0}^{2}}{25.92 a_{b \max }}
$$

The braking deceleration that the car can reach

$$
a_{b \max }=\varphi g
$$

Among them, $\mathrm{v}_{0}$ is the vehicle's initial braking speed, $t_{21}$ is the time experienced by the brake coordination, $t_{22}$ is the time experienced by the brake braking force increase, and $\varphi$ is the braking force coefficient ${ }^{[2]}$. 
According to China's "Regulations of the People's Republic of China on Road Traffic Management", the speed of motor vehicles should not be higher than $30 \mathrm{~km} / \mathrm{h}$ when driving on ice-snow roads. Therefore, most of the vehicles are at low speed when driving in severe ice and snowy weather ${ }^{[3]}$. When the car is driving at a speed lower than $30 \mathrm{~km} / \mathrm{h}$ and braking on a road with a friction coefficient of $0.1,0.2,0.3$ and 0.4 , the corresponding braking distance can be calculated, as shown in Table 2 .

Table 2 Calculation results of automobile braking distance

\begin{tabular}{|c|c|c|}
\hline $\begin{array}{c}\text { Friction } \\
\text { coefficient }\end{array}$ & Speed $(\mathrm{km} / \mathrm{h})$ & $\begin{array}{c}\text { Braking distance } \\
(\mathrm{m})\end{array}$ \\
\hline 0.1 & 10 & 4.8 \\
\hline 0.1 & 20 & 18.0 \\
\hline 0.1 & 30 & 40.9 \\
\hline 0.2 & 10 & 2.8 \\
\hline 0.2 & 20 & 9.5 \\
\hline 0.2 & 30 & 20.7 \\
\hline 0.3 & 10 & 2.1 \\
\hline 0.3 & 20 & 6.9 \\
\hline 0.3 & 30 & 14.2 \\
\hline 0.4 & 10 & 1.8 \\
\hline 0.4 & 20 & 5.6 \\
\hline 0.4 & 30 & 10.9 \\
\hline
\end{tabular}

\subsection{Simulation of vehicle braking distance on ice-snow road}

Table 3 shows the basic parameters of a certain vehicle, and Figure 2 shows the road parameter setting interface under CarSim.

Table 3 Vehicle parameter configuration

\begin{tabular}{|c|c|}
\hline Vehicle parameters & Numerical value \\
\hline Sprung mass $(\mathrm{kg})$ & 1590 \\
\hline Wheelbase $(\mathrm{mm})$ & 2800 \\
\hline $\begin{array}{c}\text { Front and rear wheelbase } \\
(\mathrm{mm})\end{array}$ & $1535 / 1265$ \\
\hline Center of mass height $(\mathrm{mm})$ & 530 \\
\hline Tire specifications & $225 / 60 \mathrm{R} 18$ \\
\hline Frontal area $\left(\mathrm{m}^{2}\right)$ & 2.8 \\
\hline
\end{tabular}

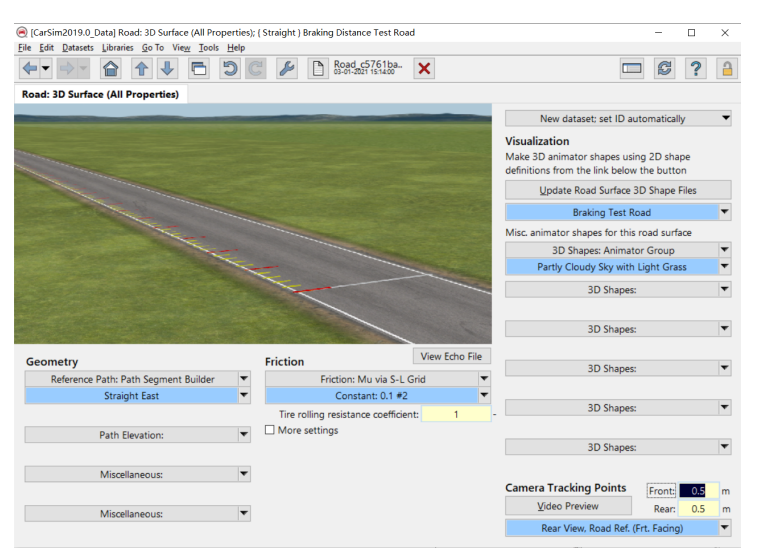

Figure 2 Road parameter setting interface

When the car is running at a speed lower than $30 \mathrm{~km} / \mathrm{h}$, the braking distance simulation test is done on a road surface with a friction coefficient of $0.1,0.2,0.3,0.4$, and the braking distance results are shown in Table 4. Taking $20 \mathrm{~km} / \mathrm{h}$ as an example, the simulation curve of the braking distance of a car on a road surface with a friction coefficient of 0.2 is shown in Figure 3.

Table 4 Simulation test results of automobile braking distance

\begin{tabular}{|c|c|c|}
\hline $\begin{array}{c}\text { Friction } \\
\text { coefficient }\end{array}$ & Speed $(\mathrm{km} / \mathrm{h})$ & $\begin{array}{c}\text { Braking distance } \\
(\mathrm{m})\end{array}$ \\
\hline 0.1 & 10 & 4.8 \\
\hline 0.1 & 20 & 17.2 \\
\hline 0.1 & 30 & 40.2 \\
\hline 0.2 & 10 & 2.7 \\
\hline 0.2 & 20 & 8.8 \\
\hline 0.2 & 30 & 20.7 \\
\hline 0.3 & 10 & 1.8 \\
\hline 0.3 & 20 & 6.8 \\
\hline 0.3 & 30 & 13.9 \\
\hline 0.4 & 10 & 1.4 \\
\hline 0.4 & 20 & 4.9 \\
\hline 0.4 & 30 & 10.5 \\
\hline
\end{tabular}

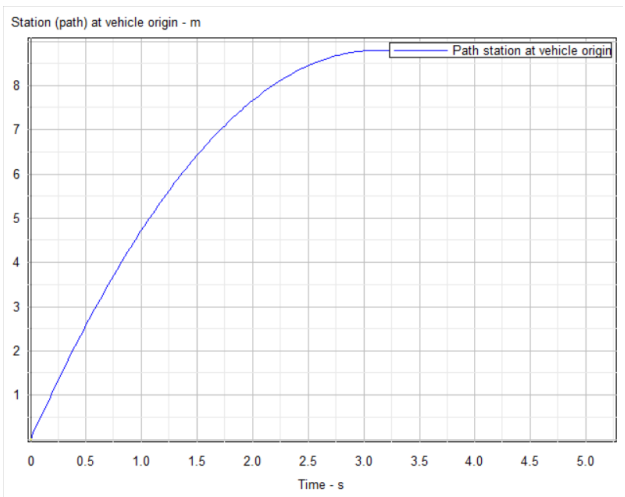

Figure 3 Simulation curve when road friction coefficient is 0.2

According to the analysis of the simulation results, the braking distance calculated by the formula is basically the same as the braking distance obtained by CarSim simulation.

\section{Simulation test of automatic emergen- cy braking system}

The automatic emergency braking system (AEB) can effectively avoid collisions or reduce injuries on roads with good adhesion coefficient in sunny weather, but there are relatively few tests on ice and slippery roads such as snowy weather. Therefore, the following will conduct simulation tests for the AEB system in snowy weather.

Because PreScan software cannot set the road friction coefficient alone, this paper uses PreScan software to establish a test simulation scene, establish a vehicle dynamics model in CarSim software, and set the road friction coefficient at the same time. Add the control algorithm under the software Matlab/Simulink for simulation test. 


\subsection{Modeling and simulation of test scenarios}

\subsubsection{Test scenario modeling}

Figure 4 shows the car simulation test scene built on the GUI interface using PreScan software. Figure 5 shows the sensor model settings. TIS sensors are added to the test vehicle. TIS1 sets the detection distance to $150 \mathrm{~m}$, the detection angle is 9 degrees, the TIS2 detection distance is $40 \mathrm{~m}$, and the detection angle is 80 degrees. Figure 6 shows the weather environment parameter settings. Figure 7 shows the Viewer interface of the PreScan software in an ice and snow scene.

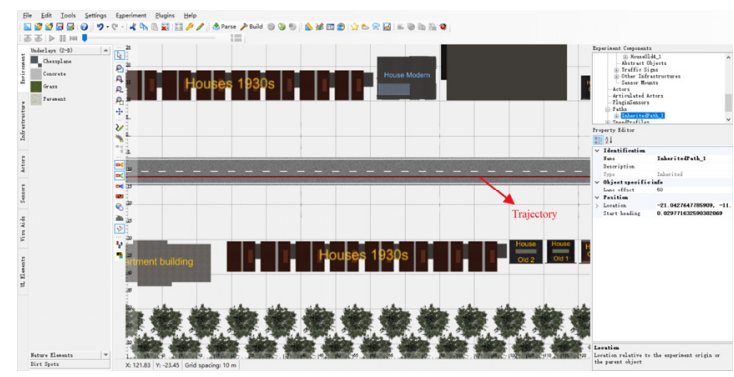

Figure 4 Road and surrounding environment settings

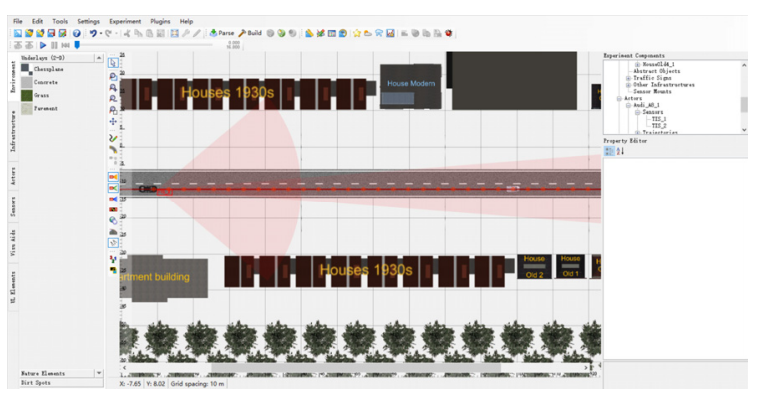

Figure 5 Vehicle and sensor settings

Figure 9 shows the weather environment parameters, which are set as the simulation frequency of the snowy weather environment. The ice and snow environment scene is displayed in the $3 \mathrm{D}$ animation as shown in Figure 10 .

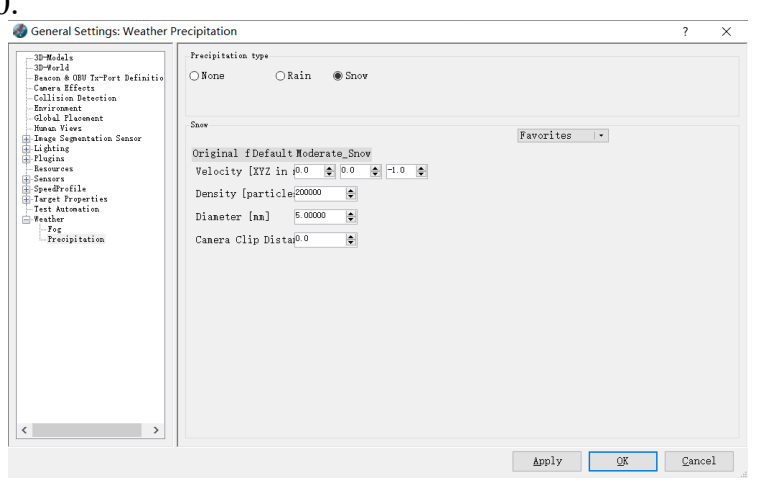

Figure 6 Setting of weather environment parameters

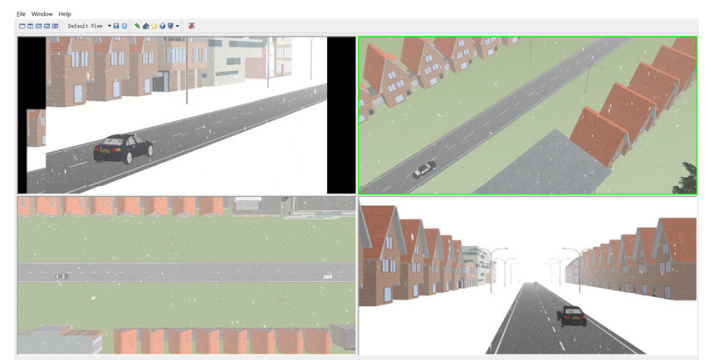

Figure 7 Viewer interface of ice and snow scene

Figure 8 shows the setting interface of the vehicle dynamics model in CarSim. Figure 9 shows the CarSim step size setting interface.

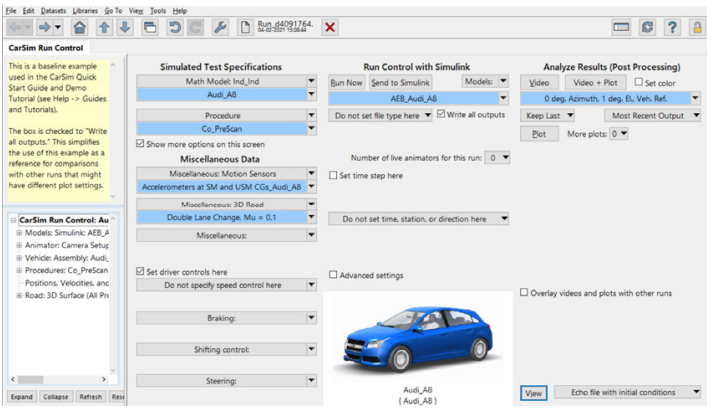

Figure 8 Setting interface of vehicle dynamics model

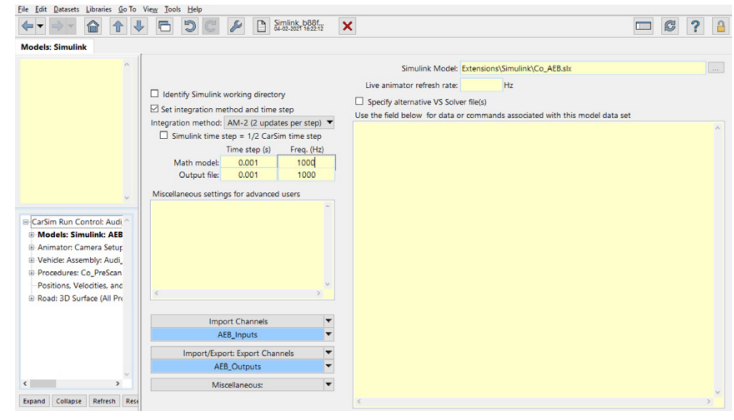

Figure 9 CarSim step length setting interface

\subsubsection{Modeling of the control model}

The TTC algorithm formula of the AEB system control model is simple ${ }^{[4]}$, and the braking time threshold can be adjusted to adapt to different working conditions, and the overall performance is better. Therefore, this paper uses the TTC algorithm to simulate the AEB system under ice -snowy roads. Figure 10 shows the main modules of the joint simulation of PreScan, Carsim and Simulink, and Figure 11 shows the input dynamics model in the CarSim software. 


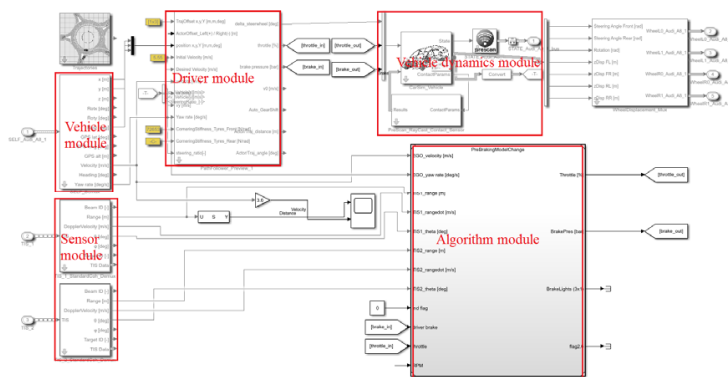

Figure 10 The main modules of test vehicle co-simulation

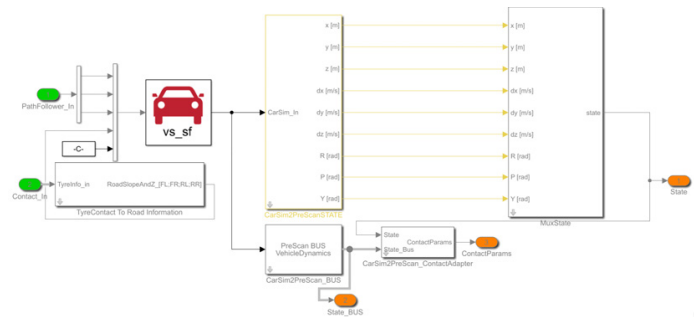

Figure 11 Input dynamics model in CarSim software

\subsection{Simulation result processing equations}

At $10 \mathrm{~km} / \mathrm{h}, 20 \mathrm{~km} / \mathrm{h}$, and $30 \mathrm{~km} / \mathrm{h}$, the CCRs scene test on ice-snow roads was performed on roads with friction coefficients of $0.1,0.2,0.3$, and 0.4 , respectively. When $\mathrm{TTC}=3.5$, the forward collision warning $(\mathrm{FCW})$ is activated to warn the driver of danger. When $\mathrm{TTC}=2.5$ and the driver does not brake, the AEB system triggers and takes $40 \%$ braking force to brake. When TTC $=1.5$ the car brakes at full force. The simulation results of the distance between the test vehicle and the target vehicle at different vehicle speeds are shown in Figure 12 to Figure 14, and the simulation results are shown in Table 5.

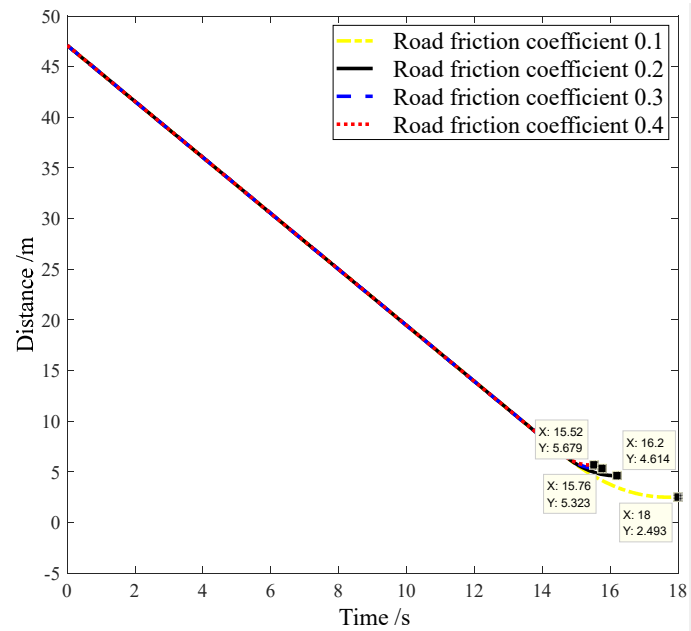

Figure 12 The change between the speed of $10 \mathrm{~km} / \mathrm{h}$ and the distance between the preceding vehicle

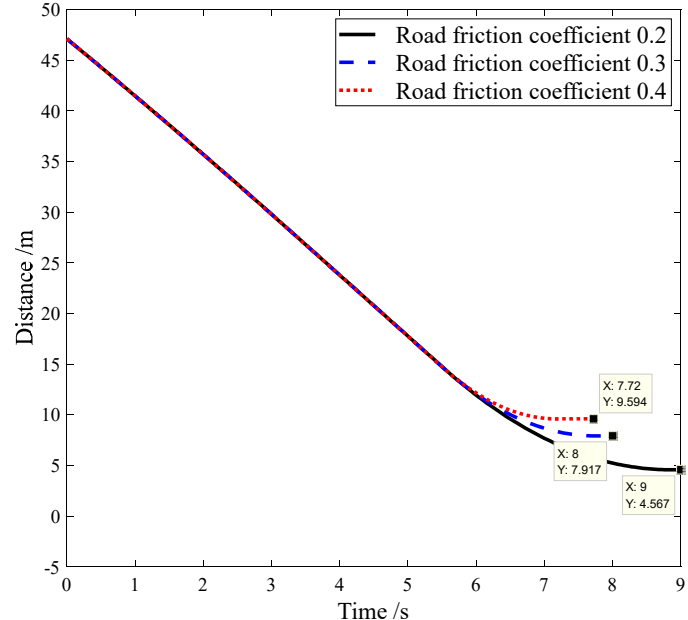

Figure 13 The change between the speed of $20 \mathrm{~km} / \mathrm{h}$ and the distance between the preceding vehicle

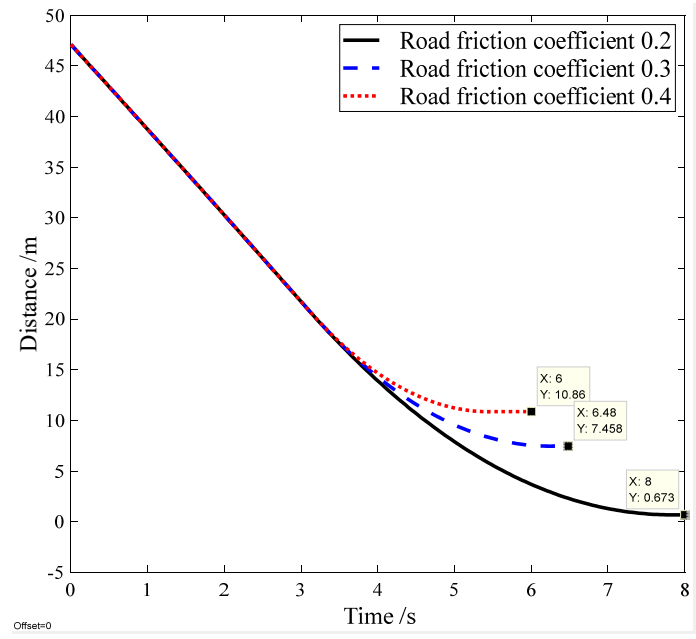

Figure 14 The change between the speed of $30 \mathrm{~km} / \mathrm{h}$ and the distance between the preceding vehicle

When the car is driving on a good road with a friction coefficient of 0.8 , the simulation result of the distance between the test vehicle and the target vehicle is shown in Figure 15.

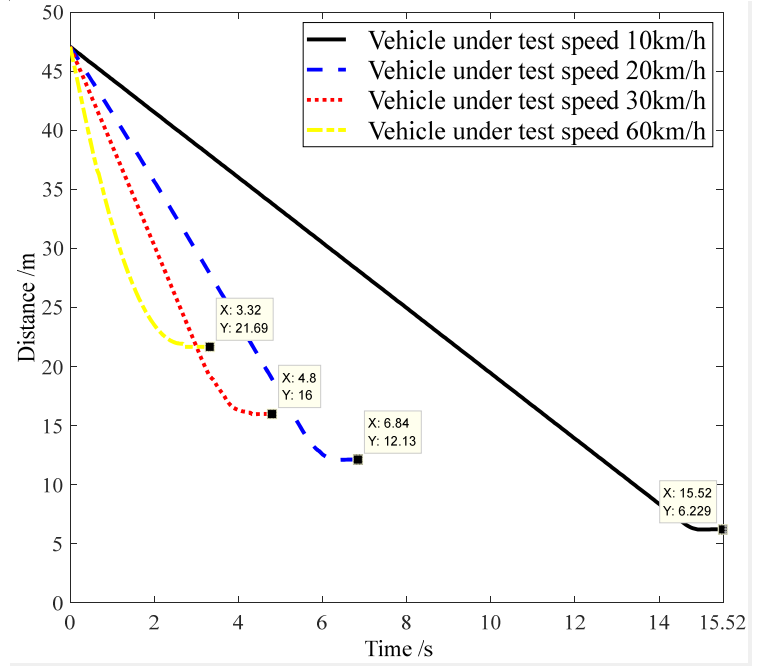

Figure 15 The change of the distance from the vehicle ahead when the road friction coefficient is 0.8 
Table 5 AEB simulation results data table under ice-snow roads

\begin{tabular}{|c|c|c|c|}
\hline $\begin{array}{c}\text { friction } \\
\text { coefficient }\end{array}$ & $\begin{array}{c}\text { Test } \\
\text { speed } \\
(\mathrm{km} / \mathrm{h})\end{array}$ & $\begin{array}{c}\text { Distance to } \\
\text { vehicle ahead }(\mathrm{m})\end{array}$ & $\begin{array}{c}\text { Whether } \\
\text { to collide }\end{array}$ \\
\hline 0.1 & 10 & 2.5 & No \\
\hline 0.1 & 20 & - & Yes \\
\hline 0.1 & 30 & - & Yes \\
\hline 0.2 & 10 & 4.6 & No \\
\hline 0.2 & 20 & 4.6 & No \\
\hline 0.2 & 30 & 0.7 & No \\
\hline 0.3 & 10 & 5.3 & No \\
\hline 0.3 & 20 & 7.9 & No \\
\hline 0.3 & 30 & 7.4 & No \\
\hline 0.4 & 10 & 5.7 & No \\
\hline 0.4 & 20 & 9.6 & No \\
\hline 0.4 & 30 & 10.8 & No \\
\hline 0.8 & 10 & 6.2 & No \\
\hline 0.8 & 20 & 12.1 & No \\
\hline 0.8 & 30 & 16.0 & No \\
\hline 0.8 & 60 & 21.7 & No \\
\hline
\end{tabular}

The results show that when the car is running at a speed of $10 \mathrm{~km} / \mathrm{h} \sim 30 \mathrm{~km} / \mathrm{h}$, it can achieve more than $83 \%$ collision avoidance on a road with a friction coefficient of $0.1,0.2,0.3,0.4$, and it cannot be used on a road with a friction coefficient of 0.1 when it is higher than $20 \mathrm{~km} / \mathrm{h}$. Achieve collision avoidance, but the vehicle speed has been reduced to $8 \mathrm{~km} / \mathrm{h}$ at the time of collision, which greatly reduces the damage to personnel and vehicles. The simulation results in Figure 15 show that when a car is driving on a good road with a friction coefficient of 0.8 , although collision avoidance can be achieved at both low speed and high speed, the car brakes too early, which will adversely affect the driver's normal driving.

\section{Conclusion}

This paper makes a test for the AEB system in ice and snow weather, and lays the foundation for the ice and snow test scenario of the AEB system. Using PreScan/CarSim software to establish scene and dynamic models can realize the test of the AEB system in the ice and snow environment. Through the adjustment of the TTC threshold, the collision avoidance effect of the car on the road with low friction coefficient can be realized. However, when the AEB system achieves this effect, the driving comfort on a good road is greatly affected, and it affects the normal driving of the driver. Therefore, when the AEB system is turned on, it can be divided into different control modes: normal mode and ice and snow mode, and different thresholds are selected, which are respectively suitable for driving on ordinary good roads and in ice and snow environments. This article only tests for straight driving conditions, and the next step will be for further testing and analysis on steering conditions.

\section{References}

1.China

Meteorological

Administration. http://www.cma.gov.cn/

2. $\mathrm{Yu}$ ZS, Automobile theory [M] Beijing (2004) Tsinghua University Press

3. State Council. (2004) Regulations for the Implementation of the Road Traffic Safety Law of the People's Republic of China. http://www.gov.cn/

4. Yang LK, Jing ST, Chen CY, Chen JJ, Mai Y.(2019) Analysis of TTC safety time threshold in FCW test of different vehicle types.[J] v.15;No.70. 16-17+76 